\title{
Impact of Ambulatory Surgery for Hemorrhoidal Disease on Clinical Outcomes and Institutional Costs
}

\section{Impacto da cirurgia ambulatória para patologia hemorroidária nos resultados clínicos e custos}

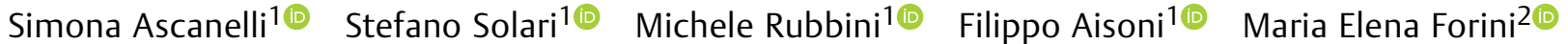 \\ Paolo Carcoforo ${ }^{1 \odot}$ \\ ${ }^{1}$ Department of Morphology, Surgery and Experimental Medicine, \\ Address for correspondence Stefano Solari, MD, Department of \\ Università degli Studi di Ferrara, Ferrara, Italy \\ 2 Health Statistics Office, Università degli Studi di Ferrara, \\ Ferrara, Italy \\ Morphology, Surgery and Experimental Medicine, Section General \\ Surgery, Azienda Ospedaliero-Universitaria Arcispedale S. Anna, \\ Ferrara. Via Aldo Moro 8, Cona - Ferrara, 44124, Italy \\ (e-mail: slrsfn@unife.it).
}

J Coloproctol 2021;41(1):14-22

\begin{abstract}
Keywords

- hemorrhoids

- hemorrhoidectomy

- transanal hemorrhoroidal dearterialization

- local anesthesia

- ligation anopexy

- ambulatory surgery
\end{abstract}

Objective Transanal hemorrhoidal artery ligation with mucopexy (ligation anopexy [LA]) and open hemorrhoidectomy $(\mathrm{OH})$ can both be performed under local anesthesia. The aim of the present study was to analyze the impact and the cost-effectiveness of performing these techniques in an ambulatory setting of an Italian academic center on the postoperative outcome.

Methods A series of 122 consecutive patients with grades II and III hemorrhoidal disease undergoing ambulatory surgical treatment of hemorrhoids in 2015 to 2018 (group A) was compared with 122 patients operated at the same institution in the same period (group $\mathrm{H}$ ) in a hospital setting.

The primary outcome was the number of days required to return to work/daily activities. Secondary outcomes included postoperative pain and complications, costeffectiveness, patient satisfaction, and recurrence at 12 months. In group A, all the procedures were performed under local anesthesia with early discharge. In group $\mathrm{H}$, the procedures were performed under general or loco-regional anesthesia with hospital admission.

Results The mean number of days required to return to work/daily activities was $8.4 \pm 4.8$ days in group $A$, compared with $12.5 \pm 3$ days in group $\mathrm{H}(p<0.001)$. The visual analog scale (VAS) pain score at 1 week, 2 and 3 weeks, and 1 month after surgery was lower for patients undergoing LA in the ambulatory setting $(p<0.01)$. We observed more postoperative complications in hospitalized (12.5\%) than in ambulatory patients $(7.5 \%)(p<0.001)$. The total mean direct costs per patient were significantly lower in the ambulatory setting versus the hospital stay group ( 351.3 versus 1,746 euros). received

July 8,2020

accepted

August 10, 2020
DOI https://doi.org/ 10.1055/s-0041-1724062. ISSN 2237-9363.

\author{
(C) 2021. Sociedade Brasileira de Coloproctologia. All rights \\ reserved. \\ This is an open access article published by Thieme under the terms of the \\ Creative Commons Attribution-NonDerivative-NonCommercial-License, \\ permitting copying and reproduction so long as the original work is given \\ appropriate credit. Contents may not be used for commercial purposes, or \\ adapted, remixed, transformed or built upon. (https://creativecommons.org/ \\ licenses/by-nc-nd/4.0/) \\ Thieme Revinter Publicações Ltda., Rua do Matoso 170, Rio de \\ Janeiro, RJ, CEP 20270-135, Brazil
}




\section{Resumo}

\author{
Palavras-chave \\ - hemorroidas \\ - hemorrhoidectomia \\ - dearterialização \\ hemorroidária \\ transanal \\ - anestesia local \\ - anopexia \\ - cirurgia ambulatória
}

\begin{abstract}
Conclusion Implementing ambulatory surgery for hemorrhoids is feasible, safe, and cost-effective.
\end{abstract}

Objetivo A ligação transanal da artéria hemorroidária com mucopexia e a hemorroidectomia aberta (HA) podem ser realizadas em anestesia local. $\mathrm{O}$ objetivo do presente estudo foi analisar o impacto no resultado pós-operatório e a relação custo-eficácia da realização destas técnicas em ambiente ambulatorial de um centro acadêmico italiano no desfecho pós-operatório.

Métodos Uma série de 122 pacientes consecutivos com patologia hemorroidária de graus II e III submetidos a cirurgia de hemorroidas em regime ambulatório de 2015 a 2018 (grupo A) foi comparada com 122 pacientes operados na mesma instituição no mesmo período (grupo $\mathrm{H}$ ) por hospitalização.

O desfecho primário foi o número de dias necessários para regressar ao trabalho/atividades diárias. Os desfechos secundários incluíram dor e complicações pós-operatórias, custo-eficácia, satisfação do paciente, e recidiva aos 12 meses. No grupo A, todos os procedimentos foram realizados em anestesia local. No grupo $\mathrm{H}$, os procedimentos foram realizados em anestesia geral ou loco-regional.

Resultados A espera média para o regresso ao trabalho foi de $8,4 \pm 4,8$ dias no grupo A em comparação com $12,5 \pm 3$ dias no grupo $\mathrm{H}(p<0,001)$. A pontuação na escala visual analógica (EVA) da dor 1 semana, 2 e 3 semanas, e 1 mês após a cirurgia foi mais baixa para os pacientes submetidos a cirurgia de ligadura com anopexia em ambiente ambulatorial $(p<0,01)$. Observamos mais complicações pós-operatórias em pacientes hospitalizados $(12,5 \%)$ do que em pacientes ambulatórios $(7,5 \%)(p<0,001)$. Os custos diretos médios totais por paciente foram mais baixos em ambiente ambulatório do que no grupo de hospitalização (351,3 contra 1.746 euros).

Conclusão A implementação da cirurgia ambulatória para hemorroidas é possível, segura e rentável.

\section{Introduction}

Hemorrhoidal disease (HD) is one of the most common benign human disorders with an incidence of $4 \%$ of the global population in the western world, with high impact on the quality of life, health systems, and social costs. ${ }^{1}$ Since the dawn of time, there have been many attempts to find a highly effective, minimally painful technique for the management of symptomatic HD. ${ }^{2}$ Surgical treatment is still guided by the grade of hemorrhoidal prolapse. ${ }^{3}$ Open hemorrhoidectomy $(\mathrm{OH})$ is considered the gold-standard treatment for symptomatic grades III and IV HD; however, it is associated with severe postoperative pain and other complications, such as urinary retention, bleeding, infection, anal stenosis, and impairment of defecation. ${ }^{4-6}$ Although various devices such as ultrasonic/ radiofrequency scalpels have been adopted to reduce posthemorrhoidectomy complications, no significant differences in postoperative complications and long-term outcomes have been reported. ${ }^{1}$ Stapled hemorrhoidopexy (SH), which was created for treating circumferential prolapsing HD, is widely used across the world, but it does not seem to offer any significant advantages over $\mathrm{OH}^{7,8}$ Non-excisional HD surgery has become more frequent during the past decade. ${ }^{4,9}$ Dopplerguided hemorrhoidal artery ligation (DGHAL), also known as transanal hemorrhoidal dearterialization (THD), ${ }^{10}$ has been demonstrated to achieve good outcomes for grades II and III HD with less postoperative pain and shorter sick leave, but increased risk of recurrence if compared with $\mathrm{OH}$ or $\mathrm{SH}^{9}{ }^{9,11,12}$ The UK National Institute for Health and Care Excellence (NICE) has affirmed that hemorrhoidal artery ligation is 'an efficacious alternative to conventional hemorrhoidectomy or stapled hemorrhoidopexy', without 'major safety concerns, ${ }^{13}$. With the help of a transanal Doppler device, terminal branches of the superior hemorrhoidal artery are detected and ligated, thus reducing the arterial inflow and causing shrinkage of hemorrhoid cushions without the need of hemorrhoid removal. Plication of hemorrhoidal prolapse is often combined to control the prolapse. Doppler guidance can help to identify the arteries, but it is not necessary for a good outcome. ${ }^{14,15}$ A simpler and cheaper technique is ligation anopexy (LA). ${ }^{16,17}$ This technique is identical to DGHAL but without the use of Doppler. Since hemorrhoidal vessels have a constant anatomical location penetrating the hemorrhoid at its base, systematically positioning ligations all around the anal canal consents to diminish the blood flow to the hemorrhoidal plexus, and to shrink the prolapsed hemorrhoids. Ligation anopexy has been proposed for grades II-III HD, with encouraging results compared with DGHAL: shorter 
operative time, feasibility under local anesthesia and as officebased, low postoperative pain, comparable short-term outcomes, lower costs, and favorable long-term outcomes. ${ }^{15,18,19}$

Hemorrhoidal disease surgery is generally performed as an inpatient procedure under general or loco regional anesthesia. However, some studies have demonstrated the feasibility and safety of performing surgery for HD in a day-case basis under local anesthesia with considerable savings in health care costs. $^{20-22}$ Still, the office-based approach for HD surgery is very rare and limited to few centers.

The aim of the present study was to determine the impact on postoperative outcome and cost-effectiveness of performing LA and $\mathrm{OH}$ in an ambulatory setting in an Italian academic center.

\section{Patients and Methods}

This retrospective observational study was designed to evaluate the impact on postoperative outcome and cost-effectiveness of performing hemorrhoids surgery in an ambulatory setting in comparison with the conventional approach with hospitalization.

The study was conducted at the Second Surgical Unit of the Azienda Ospedaliero-Universitaria Arcispedale S. Anna of Ferrara, located in the Northeast of Italy. Once the regional ethics committee's approval was obtained, data from all consecutive patients scheduled for surgery for grades II and III HD were collected over a period of 4 years (January 2015-December 2018).

The inclusion criteria were symptomatic grades II and III HD, American Society of Anesthesia (ASA) score 1 to 3, age over 18, good physical and mental health. The exclusion criteria included inflammatory bowel disease (IBD), fecal incontinence, pregnancy, previous surgery for cancer (last 12 months), severe allergy, acute thrombosed hemorrhoids, anal stricture, anal fissure, anal fistula, or medical conditions that made patients unfit for elective surgery.

Those who accepted to enter the trial were assigned to treatment by ambulatory surgery (group A) or surgery in a hospital setting (group $\mathrm{H}$ ). In either group, patients underwent $\mathrm{OH}$ or AL according to the usual clinical practice for patient care and considering the symptoms, the grade of the hemorrhoids, but also the preference of the patient, with no randomization. The same surgical team performed all surgeries.

Patient data were collected over 24 months at least. Patients were reviewed postoperatively on days $7,15,30$, and at 6, 12, and 24 months.

The primary outcome was time required to return to work/daily activities. Secondary outcomes included postoperative pain and complications, cost-effectiveness, and patient satisfaction. Hemorrhoidal disease recurrence at 12 and 24 months was registered.

All operations were performed in the supine lithotomy position. All patients were given a Fleet enema prior to surgery and intravenous antibiotic prophylaxis (metronidazole). In group A, all the procedures were performed under local anesthesia with ropivacaine $(10 \mathrm{~mL})$ intra-sphincteric injection, without sedation. In group $\mathrm{H}$, the procedures were performed under general or loco-regional anesthesia.

Ligation anopexy was performed under direct vision using an Eisenhammer rectal speculum, without the use of Doppler transducer. We placed absorbable sutures to interrupt hemorrhoidal artery blood flow $2 \mathrm{~cm}$ above the dentate line, affixing the mucosa and submucosa to the underlying internal sphincter and pulling the redundant mucosa distally in a vertical mucopexy at the same points. ${ }^{17}$ This procedure was performed for each pile. The procedure was tailored to each patient, and an average of 4 to 6 sutures at 1, 3, 5, 7, 8, and 11 of the anal clock were used during surgery. ${ }^{18}$

The Milligan-Morgan open hemorrhoidectomy $(\mathrm{OH})$ was conducted with diathermy or ultrasonic/radiofrequency scalpel. ${ }^{3}$ The number and location of the removed piles was tailored to each patient.

The patients were discharged $\sim 60$ minutes after surgery in the ambulatory setting, after meeting standard ambulatory surgery discharge criteria. At discharge, adequate painkillers and laxatives were prescribed, and an emergency telephone number was given to the patient for use in case of need. The length of hospital stay (measured by hours) was recorded. The pain levels were registered using the visual analog scale (VAS), for every day during the $1^{\text {st }}$ postoperative week, then at 2 , 3 , and 4 weeks. Adverse events (AEs) or complications were analyzed according to the Clavien Dindo Grading System applied to hemorrhoids surgery ${ }^{23}$ at day 30 after surgery, comparing them for procedure (LA versus. $\mathrm{OH}$ ) and setting (A versus. $\mathrm{H}$ ). The amount of time taken to return to work/daily activities (days) was registered. To determine the costs-effectiveness of ambulatory surgery versus hospitalization, we collected both direct and indirect costs (i.e., operating room, drugs, exams, visits, length of hospital stay, human resources, cost of complications, reoperations, and readmissions within 30 days after operation). Total costs were calculated per patient.

To evaluate patient satisfaction, the Patient Satisfaction Consultation Questionnaire (PSCQ-7) ${ }^{24}$ and Core Questionnaire Patient Satisfaction (COPS) ${ }^{25}$ were administered to all patients on the30-day follow-up visit. Hemorrhoidal disease recurrence at 12 and 24 months after operation was recorded. To assess recurrence, we used the dichotomous definition proposed by Shanmugam et al., ${ }^{26}$ meaning a healed or improved (identified with 1 ) patient who, at the end of the study period (after 12 and 24 months), did not present HD symptoms. In case of presence of symptoms, with the need for further treatment, patients were considered recurrent (identified with 2).

\section{Statistical Analysis}

The sample size calculation was guided by estimates of quicker return to daily activities or to work, following ambulatory surgery and mini-invasive surgery for HD. In a previous study, patients who underwent DGHAL had a quicker return to work compared with those who underwent $\mathrm{SH}$, with an effect size of $0.045 .{ }^{11}$ Given a matched allocation 1:1 between treatments (ambulatory patients) and control arms (hospitalized patients), and a two-sided $95.0 \%$ confidence interval for a single proportion extended to $10 \%$ on either side, with an assumed dropout rate of $5 \%$ at 6 months, 
to complete the study, a sample size of 250 subjects (125 treatment arm and 125 control group) was required.

The Shapiro-Wilk test was used to test for normality of distribution of the continuous variables. In the presence of symmetry of the distributions, the variables were represented with mean and standard deviation (SD) or, in the case of non-normal distribution, with the median value and interquartile range $(1 \mathrm{Q}-3 \mathrm{Q})$; the categorical data were expressed as total numbers and percentages. Statistical comparisons in the two groups were assessed using the Pearson's $\mathrm{X} 2$ test or Fisher exact test or Chi-squared test depending on the minimal expected count in each crosstab, using the two-way analysis of variance (ANOVA); for continuous covariates, the Student $t$ test for normally distributed variables or the Mann-Whitney test for asymmetric variables were used. All analyses were performed using Stata 15.1 SE (Stata Corporation, College Station, TX, USA). All tests were two-sided and a $p$-value of $<0.05$ was considered statistically significant.

This report complies with the strengthening the reporting of cohort studies in surgery (STROCSS) criteria. ${ }^{27}$

\section{Results}

Out of 247 patients, 3 were excluded (two for allergy and one for fecal incontinence) and 244 were allocated as follows: 122 patients underwent ambulatory treatment of hemorrhoids (group A) and 122 underwent hemorrhoid surgery in a hospital setting (group $\mathrm{H}$ ). Four patients were lost at followup, so 240 patients were studied for cost-effectiveness and safety (-Fig. 1). At baseline, groups A and H were completely well matched ( - Table $\mathbf{1}$ ). No significant difference was found in age, gender, body mass index $(\mathrm{Kg} / \mathrm{m} 2)$, ASA score, rate of work activity, and rate of previous HD surgery. No significant statistical differences were observed in the distribution of
HD grade and number of piles, or in the distribution of the two procedures (LA and $\mathrm{OH}$ ) between the two groups. The mean length of follow-up was $26.3 \pm 11.3$ months in group $A$ and $29.6 \pm 14.4$ months in group $H$. The duration of operations regardless the procedure, was significantly shorter in group A, $p<0.001$ (-Table 2). No intra-operative complications occurred. All ambulatory patients were discharged after the procedure. The median length of hospital stay in group A was of 1 hour, compared with 10 hours in group $\mathrm{H}$ $(p<0.001)$ (-Table 2). In group $\mathrm{H}$, the median hospital stay was longer for patients undergoing $\mathrm{OH}$ (27 hours) compared with patients undergoing LA (10 hours); $p<0.001$.

The median VAS pain score at 1 week, 2 and 3 weeks, and 1 month after surgery was lower and reported only in the $1^{\text {st }}$ postoperative week in group $A$ than in group $\mathrm{H}$, in which the median VAS was higher and registered until 4 weeks after surgery; $p<0.01$ (-Fig. 2). Focusing on the procedures, patients undergoing LA reported significantly lower VAS score in comparison with patients undergoing $\mathrm{OH}$ $(p<0.01)$. The mean number of days to return to work/daily activities was $8.4 \pm 4.8$ days in group $A$, compared with $12.5 \pm 3$ days in group $\mathrm{H}(p<0.001)$, regardless of the different procedures ( $\mathbf{- T a b l e ~} \mathbf{2}$ ).

We observed more postoperative complications in hospitalized patients (12.5\%) than in ambulatory patients (7.5\%), $p<0.001$; postoperative urinary retention was more frequent in group $\mathrm{H}(5.8 \%)$ than in group $\mathrm{A}(0.8 \%), p<0.01$, likely due to spinal anesthesia ( - Table 3 ). We did not observe any early post-operative hemorrhage. Overall morbidity (only grade I and II according to Clavien-Dindo classification) was $12.3 \%$ after LA procedure and $7.9 \%$ after $\mathrm{OH}$ procedure $(p<0.01)$, regardless of the operation setting. Few grade-one anal complications were observed without any significant statistical difference between groups $\mathrm{A}$ and H. However, hemorrhoids thrombosis occurred only after LA in both

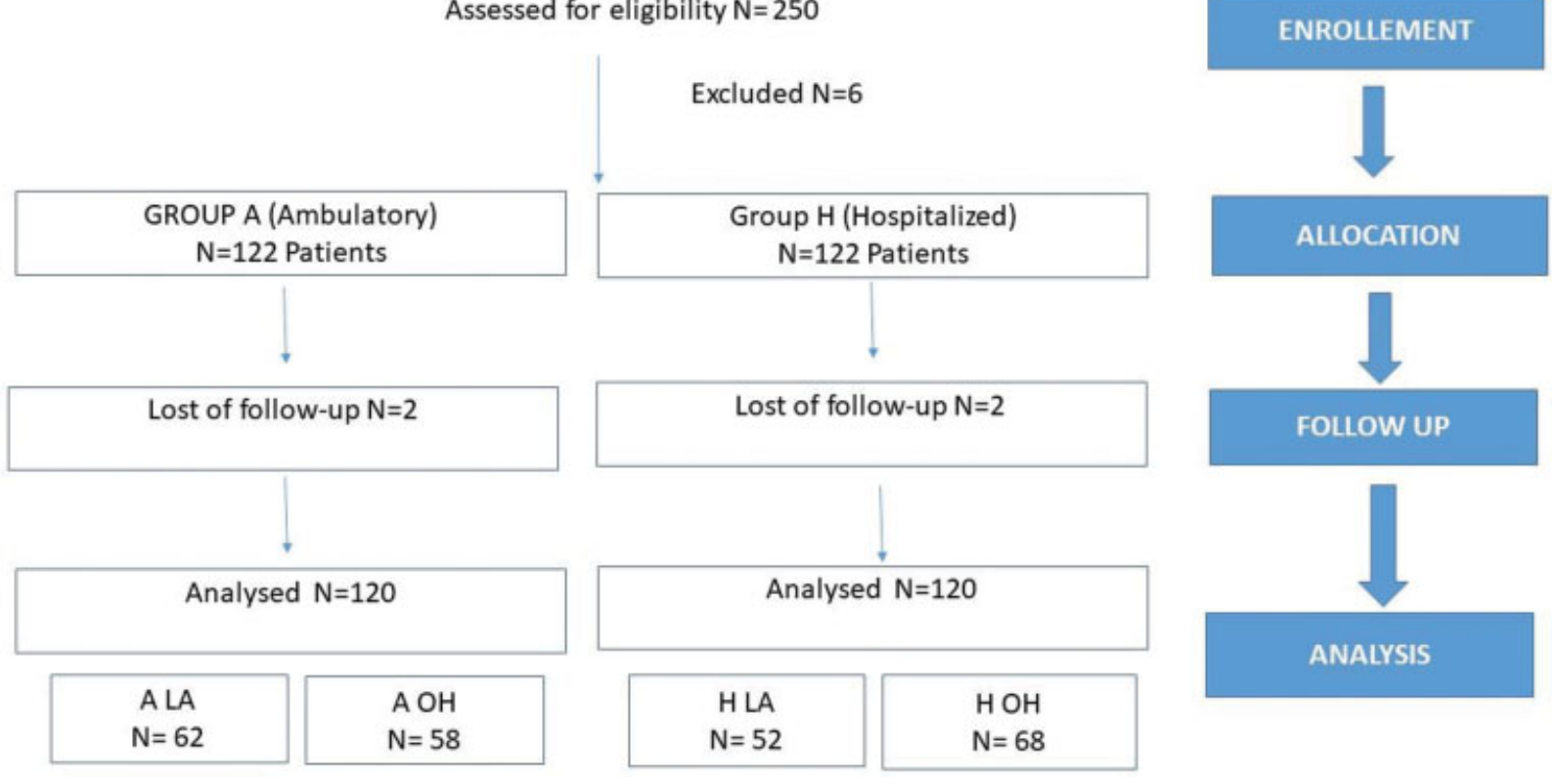

Fig. 1 Study design. 
Table 1 Patient characteristics at baseline

\begin{tabular}{|c|c|c|c|}
\hline Variable & $\begin{array}{l}\text { Group A } \\
\text { Ambulatory }\end{array}$ & $\begin{array}{l}\text { Group H } \\
\text { Hospitalized }\end{array}$ & $P$-value \\
\hline Age $($ mean $\pm S D)$ & $54.07 \pm 12.07$ & $53.16 \pm 11.8$ & NS \\
\hline Females (N. \%) & $74(61.7)$ & $61(50.8)$ & NS \\
\hline Males (N, \%) & $46(38.3)$ & $59(49.2)$ & NS \\
\hline $\begin{array}{l}\text { Body Mass Index } \\
(\mathrm{Kg} / \mathrm{m} 2)(\mathrm{N}, \%)\end{array}$ & & & NS \\
\hline$<25$ & $100(83.3)$ & $97(80.8)$ & \\
\hline $25-29.9$ & $17(14.2)$ & $20(16.7)$ & \\
\hline$>30$ & $3(2.5)$ & $3(2.5)$ & \\
\hline $\begin{array}{l}\text { American Society } \\
\text { of Anesthesia } \\
\text { score (N. \%) }\end{array}$ & & & NS \\
\hline ASA I & $73(60.8)$ & $71(59.2)$ & \\
\hline ASA II & $39(32.5)$ & $39(32.5)$ & \\
\hline ASA III & $38(6.7)$ & $10(8.3)$ & \\
\hline $\begin{array}{l}\text { Work activity } \\
(\mathrm{N}, \%)\end{array}$ & $103(85.8)$ & $102(85)$ & NS \\
\hline $\begin{array}{l}\text { Previous surgery } \\
\text { for hemorrhoids } \\
(\mathrm{N}, \%)\end{array}$ & $6(5)$ & $12(10)$ & NS \\
\hline $\begin{array}{l}\text { Grade } 2 \\
\text { hemorrhoids } \\
(\mathrm{N}, \%)\end{array}$ & $54(45)$ & $50(41.7)$ & NS \\
\hline $\begin{array}{l}\text { Grade } 3 \\
\text { hemorrhoids } \\
(\mathrm{N}, \%)\end{array}$ & $66(55)$ & $70(58.3)$ & NS \\
\hline Number of piles & & & NS \\
\hline 1 & 9 & 5 & \\
\hline 2 & 30 & 36 & \\
\hline 3 & 63 & 63 & \\
\hline 4 & 10 & 7 & \\
\hline 5 & 8 & 9 & \\
\hline LA (N, \%) & $62(54.4)$ & $52(45.6)$ & NS \\
\hline $\mathrm{OH}(\mathrm{N}, \%)$ & $58(46)$ & $68(54)$ & NS \\
\hline $\begin{array}{l}\text { Length of follow-up } \\
\text { (months) (mean } \pm \text { SD) }\end{array}$ & $26.3 \pm 11.3$ & $29.6 \pm 14.4$ & NS \\
\hline
\end{tabular}

Abbreviations: LA, ligation anopexy; $\mathrm{N}$, number; $\mathrm{OH}$, open hemorrhoidectomy; SD, standard deviation; NS, not significant. settings (4.8\% in group $A$, and $5,7 \%$ in group $H$ ), $p<0.01$. Urgency or mild fecal incontinence occurred in two patients operated on $\mathrm{OH}$. One patient of $\mathrm{H}$ group required prolonged hospital stay for severe pain occurred after $\mathrm{OH}$ ( - Table 3 ). None of the patients required readmission, blood transfusion or reoperation within 30 days after surgery. No grade III, IV, and $\mathrm{V}$ complications were described in both groups.

There was no significant difference between group A (4.2\%) and group $\mathrm{H}$ (3.3\%) concerning recurrence at 12 months (-Table 2). However, comparing the surgical procedures, recurrence was significantly higher for LA (6.4\% in group $\mathrm{A}$ and $7.7 \%$ in group $\mathrm{H})$ than $\mathrm{OH}(1.7 \%$ and $0 \%$ respectively) $(p<0.01)$; in particular, persistent hypertrophic external skin tags and recurrent hemorrhoidal prolapse were the most common long-term complications observed after LA.

The rate of reoperation, which consisted of $\mathrm{OH}$ procedure in each recurrent patient, was 2.5\% in Group A and 1.6\% in group $\mathrm{H}$ (p: NS). HD recurrence after 24 months was stable: $2.5 \%$ in group $A$ and $1.6 \%$ in group $\mathrm{H}$, occurring in both groups after LA procedure (-Table $\mathbf{2}$ ).

Cost analysis evidenced that the total mean institutional costs per patient were significantly lower in ambulatory setting (351.3 euros) compared with hospitalized regimen (1,746 euros); $p<0.001$ ( - Table 4 ).

Patient satisfaction according to the COPS and PSCQ-7 questionnaire was high in both groups: the $97 \%$ of patients operated in an ambulatory setting reported that they would repeat the procedure under local anesthesia and with early discharge after the procedure.

\section{Discussion}

Hemorrhoidal disease can be managed appropriately and successfully in an outpatient setting, with early discharge, better pain control, lower postoperative complications, considerable savings in health care costs, and high patient satisfaction. We observed that both $\mathrm{LA}$ and $\mathrm{OH}$ could be performed in an outpatient setting with a superiority of LA over $\mathrm{OH}$ for shorter operative times and lower postoperative pain scores (-Fig. 2), as confirmed by the current literature. ${ }^{16,17,28,29}$ The

Table 2 Early and late postoperative outcomes

\begin{tabular}{|l|l|l|l|l|l|l|l|}
\hline & \multicolumn{2}{l|}{ Ambulatory } & \multicolumn{2}{l|}{ Hospitalized } & $P$-value \\
\hline & $\begin{array}{l}\text { Group A } \\
120\end{array}$ & $\begin{array}{l}\text { LA } \\
62\end{array}$ & $\begin{array}{l}\text { OH } \\
58\end{array}$ & $\begin{array}{l}\text { Group H } \\
120\end{array}$ & $\begin{array}{l}\text { LA } \\
52\end{array}$ & $\begin{array}{l}\text { OH } \\
68\end{array}$ \\
\hline $\begin{array}{l}\text { Length of procedure (min) } \\
\text { Mean } \pm \text { SD }\end{array}$ & $27.5 \pm 9.3$ & $22.2 \pm 6.6$ & $33.7 \pm 7.9$ & $32.4 \pm 8.4$ & $28.9 \pm 8.4$ & $35.07 \pm 7.5$ & $<0.001$ \\
\hline $\begin{array}{l}\text { Hospital length of stay (hours) } \\
\text { Median (range) }\end{array}$ & $1(1-2)$ & $1(1-2)$ & $1(1-3)$ & $10(8-120)$ & $10(8-28)$ & $27(9-120)$ & $<0.001$ \\
\hline $\begin{array}{l}\text { Return to work/daily activities (days) } \\
\text { Mean } \pm \text { SD }\end{array}$ & $8.4 \pm 4.8$ & $8.5 \pm 4.7$ & $8.4 \pm 4.9$ & $12.5 \pm 3$ & $12.05 \pm 2.9$ & $12.9 \pm 3.04$ & $<0.001$ \\
\hline HD recurrence at 12 months (N, \%) & $5(4.2)$ & $4(6.4)$ & $1(1.7)$ & $4(3.3)$ & $4(7.7)$ & - & $<0.01$ \\
\hline Reoperation after 12 months (N, \%) & $3(2.5)$ & $3(4.8)$ & - & $2(1.6)$ & $2(3.8)$ & - & NS \\
\hline HD recurrence at 24 months (N, \%) & $3(2.5)$ & $3(4.8)$ & - & $2(1.6)$ & $2(3.8)$ & - & NS \\
\hline
\end{tabular}

Abbreviations: HD, hemorrhoidal disease; LA, ligation anopexy; N, number; OH, open hemorrhoidectomy; SD, standard deviation; NS, not significant. 


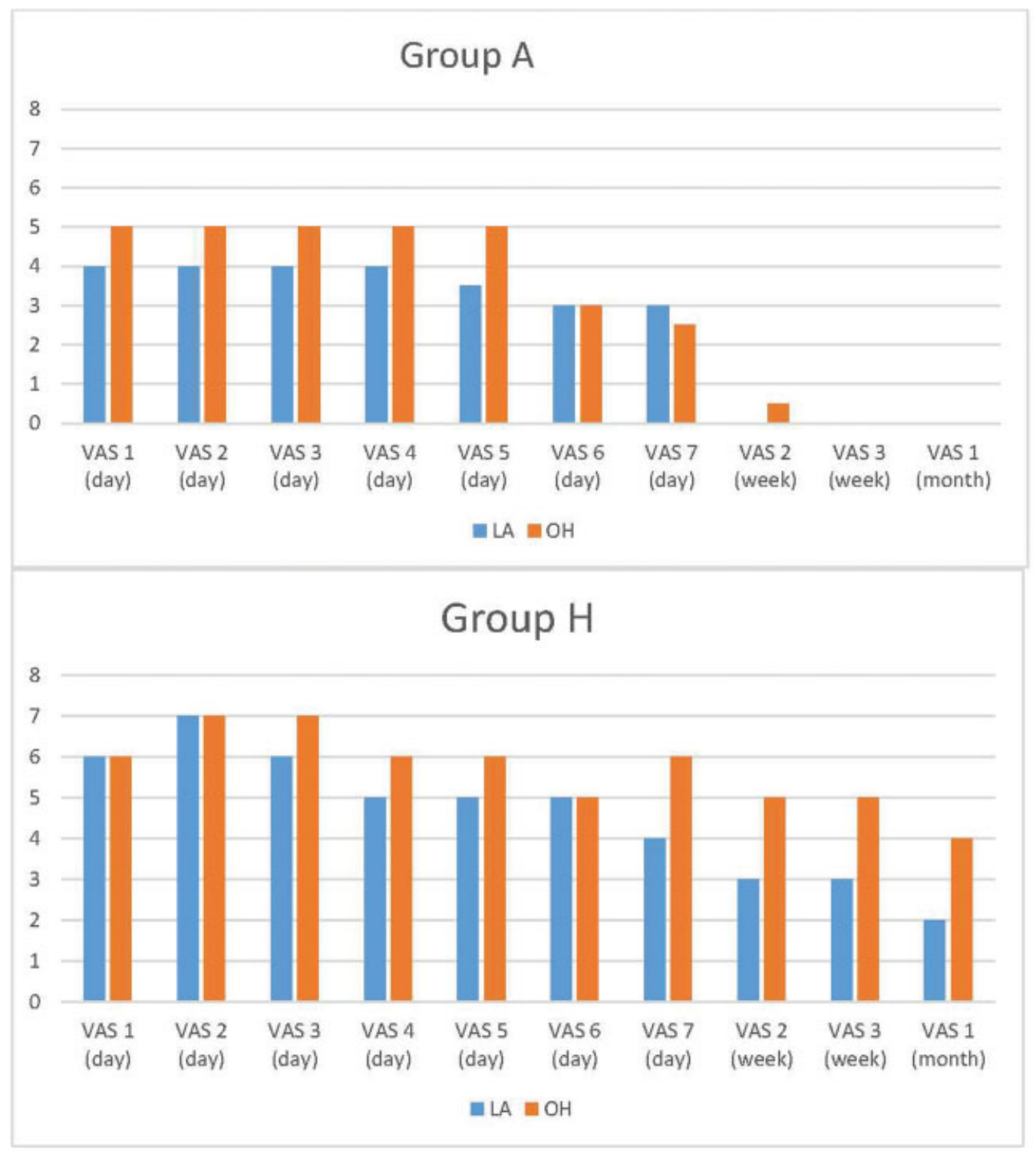

VAS (Visual analogic scale) median values at 1 week, 2 weeks, 3 weeks, and 1 month after surgery

\section{LA: ligation anopexy $\mathrm{OH}$ : open hemorrhoidectomy}

Fig. 2 Postoperative pain in group $\mathrm{A}$ and group $\mathrm{H}$.

lower pain scores associated with LA might be explained by the placement of sutures in the non-sensitive anal mucosa above the dentate line, ${ }^{30}$ as well as the absence of surgical wounds. The registration of higher VAS score after $\mathrm{OH}$ was explained by the thermal effect of diathermy, the presence of wounds in the sensitive anal mucosa, and anal spasm. On the other hand, the sutures performed during LA may cause a venous stasis, thus increasing the risk of thrombosis. In fact, our results confirmed that thrombosis of the hemorrhoidal veins occurred only after LA in both settings ( - Table 3 ).

Concerning postoperative complications, hospitalized patients seemed to have more postoperative complications (12.5\%), compared with ambulatory patients (7.5\%), due to the higher rate of urinary retention (5.7\%) after spinal anesthesia; however, focusing the attention on the proce- dure, we observed that overall morbidity was $12.3 \%$ after LA and $7.9 \%$ after $\mathrm{OH}$, regardless of the setting. In fact, even if LA is considered a less invasive technique, it is not without complications: in a larger Italian series in which all patients underwent DGHAL under general or spinal anesthesia, significant postoperative pain and urinary retention were reported by $13 \%$ and $8.6 \%$ of the patients, with an overall morbidity of $18 \%{ }^{31}$ When DGHAL was compared with SH and $\mathrm{OH}$ in two randomized control trials (RCTs), respectively, ${ }^{11,32}$ patients undergoing DGHAL had less postoperative pain and a faster return to work, without producing a significantly higher risk in terms of AEs. A recent open-label $\mathrm{RCT}$ comparing THD with minimal $\mathrm{OH}$ reported that minimal $\mathrm{OH}$ had an immediate postoperative course, similar to DGHAL. $^{33}$ 
Table 3 Postoperative complications (within 30 days after surgery)

\begin{tabular}{|l|l|l|l|l|l|l|l|}
\hline & \multicolumn{2}{|l|}{ Ambulatory } & \multicolumn{2}{l|}{ Hospitalized } & P-value \\
\hline & $\begin{array}{l}\text { Group A } \\
120\end{array}$ & $\begin{array}{l}\text { LA } \\
62\end{array}$ & $\begin{array}{l}\text { OH } \\
58\end{array}$ & $\begin{array}{l}\text { Group H } \\
120\end{array}$ & $\begin{array}{l}\text { LA } \\
52\end{array}$ & $\begin{array}{l}\text { OH } \\
68\end{array}$ & \\
\hline $\begin{array}{l}\text { Overall postoperative complications } \\
\text { (Clavien-Dindo) } \\
\text { (N, \%) }\end{array}$ & $9(7.5)$ & $5(8.1)$ & $4(6.9)$ & $15(12.5)$ & $9(17.3)$ & $6(8.8)$ & $<0.001$ \\
\hline Grade I & $9(7.5)$ & $5(8.1)$ & $4(6.8)$ & $14(11.7)$ & $9(17.3)$ & $5(7.3)$ & $<0.01$ \\
\hline $\begin{array}{l}\text { Grade I } \\
\text { urinary retention }\end{array}$ & $1(0.8)$ & - & $1(1.7)$ & $7(5.8)$ & $4(7.7)$ & $3(4.4)$ & $<0.01$ \\
\hline Grade I & $8(6.6)$ & $5(8.1)$ & $3(5.1)$ & $7(5.8)$ & $5(9.6)$ & $2(2.9)$ & NS \\
\hline Anal complications & & & & & & & \\
\hline Bleeding & - & - & - & - & - & - & \\
\hline Thrombosed hemorrhoids & $3(2.5)$ & $3(4.8)$ & - & $3(2.5)$ & $3(5.7)$ & - & $<0.01$ \\
\hline Prolapse & - & - & - & - & - & - & NS \\
\hline Fissure & $2(1.6)$ & $1(1.6)$ & $1(1.5)$ & $2(1.6)$ & $1(1.9)$ & $1(1.5)$ & NS \\
\hline Stenosis & - & - & - & - & - & - & NS \\
\hline Impaction & $1(0.8)$ & - & $1(1.5)$ & - & - & - & NS \\
\hline Local infection & $1(0.8)$ & $1(1.6)$ & - & $1(0.8)$ & $1(1.9)$ & - & NS \\
\hline Urgency or mild incontinence & $1(0.8)$ & - & $1(1.5)$ & $1(0.8)$ & - & $1(1.5)$ & NS \\
\hline $\begin{array}{l}\text { Grade II } \\
\text { persistent pain with prolonged hospital stay }\end{array}$ & 0 & - & - & $1(0.8)$ & - & $1(1.5)$ & NS \\
\hline
\end{tabular}

Abbreviations: LA, ligation anopexy; OH, open hemorrhoidectomy; NS, not significant.

Complications according to the Clavien-Dindo grading system in relation with the setting and the type of procedure.

Table 4 Comparison of institutional costs per patient between groups A and $\mathrm{H}$ (mean and standard deviation)

\begin{tabular}{|l|l|l|l|}
\hline Variable & Ambulatory & Hospitalized & $P$-value \\
\hline Operating room (pharmacy, equipment, staff, operating theater) (Euro) & $275 \pm 0$ & $408 \pm 182.0$ & $<0.001$ \\
\hline Surgical ward (hospital stay, pharmacy, laboratory) (Euro) & 0 & $1237.5 \pm 262.7$ & $<0.001$ \\
\hline Outpatient clinic visits (Euro) & $76.33 \pm 23.02$ & $116 \pm 32.14$ & $<0.001$ \\
\hline Total mean institutional costs per patient (Euro) & $351.3 \pm 23$ & $1746.4 \pm 347.01$ & $<0.001$ \\
\hline
\end{tabular}

Regarding the resumption time of work and daily activities, used as primary index of clinical outcome, we observed that the mean time of return to work/daily activities was 8.4 days in group A compared with 12.5 days in group $H$, regardless of the different operations (-Table 2). This result might be explained by cultural and socioeconomic reasons: patients who preferred the ambulatory setting with simpler preoperative preparation, easier hospital access and much shorter hospital stay might be better disposed to a faster recovery and an earlier return to normal daily activities. However, this analysis might be influenced by the retrospective design of the trial, which represents a limitation to the present study. The setting (ambulatory or hospitalization) was chosen considering the symptoms, the grade of hemorrhoids, but also the preference of the patient and the indication of the surgeon, with no randomization. To overcome this limitation, a further blinded randomized controlled study comparing $\mathrm{OH}$ and LA performed in an ambulatory setting is needed.

A debated topic is recurrence after minimally invasive HD surgery. The two techniques showed different results regarding long-term recurrence rate. While overall HD recurrence at 12 months was low and similar in both settings ( $4.2 \%$ in group A vs $3.3 \%$ in group $\mathrm{H}$ ), when we compared the surgical procedures, recurrence was significantly higher for LA (6.4\% in group A and $7.7 \%$ in group $\mathrm{H}$ ) than $\mathrm{OH}(1.7 \%$ and $0 \%$ respectively) (-Table 2 ). Hemorrhoidal disease recurrence after 24 months was stable, confirming that recurrence after LA occurs within 12 months and does not increase further. ${ }^{17}$ Compared with the current literature, in which residual or recurrent HD after DGHAL ranges between 0 and 20\%,11,12,15-19,29,31-34 the recurrence rate reported in our study is acceptable and justifies LA as a valid surgical option for HD even in grade III. 
Concerning cost analysis, we highlighted that the total mean institutional costs per patient were much lower in the ambulatory setting. This can be easily explained as the officebased procedures were performed under local anesthesia, requiring fewer professionals and with significant savings of all the costs associated with hospitalization. Local anesthesia guarantees an excellent relaxation of the anal sphincter, ${ }^{20}$ allowing the surgeon to perform the operation under the same conditions obtained with general or loco-regional anesthesia, but with a lower risk of urinary retention. ${ }^{21,22}$ Considering the good results reported above, ambulatory surgery for HD showed an excellent cost-effectiveness ratio and should be contemplated in all Italian institutions for the treatment of grades II and III HD. Healthcare institutions have an increasing need for cost savings, so ambulatory surgery is an interesting option for low-complexity surgery when possible, reserving valuable resources for high- complexity interventions with the need of hospitalization. Moreover, this approach would enable a wider range of hospitals to offer hemorrhoid surgery, and especially in peripheral areas.

\section{Conclusions}

Our study suggests that HD can be successfully treated in an outpatient facility, under local anesthesia, and using less aggressive surgery. Both LA and $\mathrm{OH}$ techniques are safe and cost-effective for ambulatory surgical treatment of grades II and III hemorrhoids; however, a better anatomical correction with only a minimal increase in pain, no additional morbidity, and low recurrence rate make $\mathrm{OH}$ the ideal technique even in an ambulatory setting.

Trial registration number: UHFerrara130575, approved on $20 / 06 / 2013$.

The work described has not been published before, but it was selected for oral presentation at ESCP's 13th Scientific and Annual Meeting that took place 26-28 September 2018 in Nice, France

Ascanelli S, Solari S, Occhionorelli S, Carcoforo P. Impact of office-based surgery for hemorrhoids on clinical outcome and institutional costs: a prospective controlled study. Colorectal Dis 2018: 20 (Suppl.4): 6-17.

The work is original and neither published, accepted, or submitted elsewhere, its publication has been approved by all co-authors, as well as by the responsible authorities tacitly or explicitly - at the institute where the work has been performed.

The authors have read and complied with author guidelines.

\section{Authorship}

Simona Ascanelli: Study conception and design; acquisition, analysis, or interpretation of data; drafting and critical revision of the work for important intellectual content; and final approval of the version to be published. Stefano Solari: Acquisition, analysis, or interpretation of data; drafting and critical revision of the work for important intellectual content; and final approval of the version to be published.
Michele Rubbini: Critical revision of the work for important intellectual content; final approval of the version to be published; and agreement to be accountable for all aspects of the work, ensuring that questions related to the accuracy or integrity of any part of the work are appropriately investigated and resolved.

Filippo Aisoni: Acquisition, analysis, or interpretation of data; critical revision of the work for important intellectual content; and final approval of the version to be published.

Elena Forini: Acquisition, analysis, or interpretation of data; critical revision of the work for important intellectual content; and final approval of the version to be published. Paolo Carcoforo: Study conception; critical revision fo the work for important intellectual content; final approval of the version to be published; and agreement to be accountable for all aspects of the work, ensuring that questions related to the accuracy or integrity of any part of the work are appropriately investigated and resolved.

\section{Conflict of Interests}

The authors have no conflict of interests to declare.

\section{References}

1 Sun Z, Migaly J. Review of hemorrhoid disease: presentation and management. Clin Colon Rectal Surg 2016;29(01):22-29. Doi: 10.1055/s-0035-1568144

2 Wexner SD. The quest for painless surgical treatment of hemorrhoids continues. J Am Coll Surg 2001;193(02):174-178

3 Rivadeneira DE, Steele SR, Ternent C, Chalasani S, Buie WD, Rafferty JLStandards Practice Task Force of The American Society of Colon and Rectal Surgeons. Practice parameters for the management of hemorrhoids (revised 2010). Dis Colon Rectum 2011; 54(09):1059-1064. Doi: 10.1097/DCR.0b013e318225513d

4 Lohsiriwat V. Treatment of hemorrhoids: A coloproctologist's view. World J Gastroenterol 2015;21(31):9245-9252. Doi: 10.3748/wjg.v21.i31.9245

5 Ho YH, Buettner PG. Open compared with closed haemorrhoidectomy: meta-analysis of randomized controlled trials. Tech Coloproctol 2007;11(02):135-143. Doi: 10.1007/s10151-007-0343-0

6 Yeo D, Tan KY. Hemorrhoidectomy - making sense of the surgical options. World J Gastroenterol 2014;20(45):16976-16983. Doi: 10.3748/wjg.v20.i45.16976

7 Chen HL, Woo XB, Cui J, Chen CQ Peng JS. Ligasure versus stapled hemorrhoidectomy in the treatment of hemorrhoids: a meta-analysis of randomized control trials. Surg Laparosc Endosc Percutan Tech 2014;24(04):285-289. Doi: 10.1097/SLE.0000000000000009

8 Tjandra JJ, Chan MK. Systematic review on the procedure for prolapse and hemorrhoids (stapled hemorrhoidopexy). Dis Colon Rectum 2007;50(06):878-892. Doi: 10.1007/s10350-006-0852-3

9 Giordano P, Overton J, Madeddu F, Zaman S, Gravante G. Transanal hemorrhoidal dearterialization: a systematic review. Dis Colon Rectum 2009;52(09):1665-1671. Doi: 10.1007/DCR.0b013e3181af50f4

10 Ratto C, de Parades V. Doppler-guided ligation of hemorrhoidal arteries with mucopexy: A technique for the future. J Visc Surg 2015;152(2, Suppl):S15-S21. Doi: 10.1016/j.jviscsurg.2014.08.003

11 Lehur PA, Didnée AS, Faucheron J-L, et al; LigaLongo Study Group. Cost-effectiveness of New Surgical Treatments for Hemorrhoidal Disease: A Multicentre Randomized Controlled Trial Comparing Transanal Doppler-guided Hemorrhoidal Artery Ligation With Mucopexy and Circular Stapled Hemorrhoidopexy. Ann Surg 2016;264(05):710-716. Doi: 10.1097/SLA.0000000000001770 
12 Xu L, Chen H, Lin G, Ge Q, Qi H, He X. Transanal hemorrhoidal dearterialization with mucopexy versus open hemorrhoidectomy in the treatment of hemorrhoids: a meta-analysis of randomized control trials. Tech Coloproctol 2016;20(12):825-833. Doi: 10.1007/s10151016-1551-2

13 National Institute for Health and Clinical Excellence. Interventional Procedure Guidance (2013) Haemorrhoidal Artery Ligation. http://www.nice.org.uk/nicemedia/live/12236/48673/48673.pdf

14 Gupta PJ, Kalaskar S, Taori S, Heda PS. Doppler-guided hemorrhoidal artery ligation does not offer any advantage over suture ligation of grade 3 symptomatic hemorrhoids. Tech Coloproctol 2011;15(04):439-444. Doi: 10.1007/s10151-011-0780-7

15 Zhai M, Zhang YA, Wang ZY, et al. A Randomized Controlled Trial Comparing Suture-Fixation Mucopexy and Doppler-Guided Hemorrhoidal Artery Ligation in Patients with Grade III Hemorrhoids. Gastroenterol Res Pract 2016;2016:8143703. Doi: 10.1155/2016/ 8143703

16 Hussein AM. Ligation-anopexy for treatment of advanced hemorrhoidal disease. Dis Colon Rectum 2001;44(12):1887-1890. Doi: 10.1007/BF02234474

17 Gupta PJ, Kalaskar S. Ligation and mucopexy for prolapsing hemorrhoids-a ten year experience. Ann Surg Innov Res 2008; 2:5. Doi: 10.1186/1750-1164-2-5

18 Elshazly WG, Gazal AE, Madbouly K, Hussen A. Ligation anopexy versus hemorrhoidectomy in the treatment of second- and thirddegree hemorrhoids. Tech Coloproctol 2015;19(01):29-34. Doi: 10.1007/s10151-014-1235-8

19 Schuurman JP, Borel Rinkes IH, Go PMNY. Hemorrhoidal artery ligation procedure with or without Doppler transducer in grade II and III hemorrhoidal disease: a blinded randomized clinical trial. Ann Surg 2012;255(05):840-845. Doi: 10.1097/SLA.0b013e31824e2bb5

20 Lohsiriwat D, Lohsiriwat V. Outpatient hemorrhoidectomy under perianal anesthetics infiltration. J Med Assoc Thai 2005;88(12): 1821-1824http://www.medassocthai.org/journal

21 Haveran LA, Sturrock PR, Sun MY, et al. Simple harmonic scalpel hemorrhoidectomy utilizing local anesthesia combined with intravenous sedation: a safe and rapid alternative to conventional hemorrhoidectomy. Int J Colorectal Dis 2007;22(07):801-806. Doi: $10.1007 / \mathrm{s} 00384-006-0242-2$

22 Delikoukos S, Zacharoulis D, Hatzitheofilou C. Stapled hemorrhoidectomy under local anesthesia: tips and tricks. Dis Colon Rectum 2005;48(11):2153-2155. Doi: 10.1007/s10350-005-0178-6

23 Dindo D, Demartines N, Clavien PA. Classification of surgical complications: a new proposal with evaluation in a cohort of 6336 patients and results of a survey. Ann Surg 2004;240(02): 205-213. Doi: 10.1097/01.sla.0000133083.54934.ae

24 Frostholm L, Fink P, Oernboel E, et al. The uncertain consultation and patient satisfaction: the impact of patients' illness percep- tions and a randomized controlled trial on the training of physicians' communication skills. Psychosom Med 2005;67(06): 897-905. Doi: 10.1097/01.psy.0000188403.94327.5b

25 Kleefstra SM, Kool RB, Veldkamp CM, et al. A core questionnaire for the assessment of patient satisfaction in academic hospitals in The Netherlands: development and first results in a nationwide study. Qual Saf Health Care 2010;19(05):e24. Doi: 10.1136/ qshc.2008.030825

26 Shanmugam V, Thaha MA, Rabindranath KS, Campbell KL, Steele RJC, Loudon MA. Systematic review of randomized trials comparing rubber band ligation with excisional haemorrhoidectomy. $\mathrm{Br}$ J Surg 2005;92(12):1481-1487. Doi: 10.1002/bjs.5185

27 Agha RA, Borrelli MR, Vella-Baldacchino M, Thavayogan R, Orgill DPSTROCSS Group. The STROCSS statement: strengthening the reporting of cohort studies in surgery. Int J Surg 2017; 46:198-202. Doi: 10.1016/j.jjsu.2017.08.586

28 Bronstein M, Issa N, Gutman M, Neufeld D. Ligation under vision of haemorrhoidal cushions for therapy of bleeding haemorrhoids. Tech Coloproctol 2008;12(02):119-122. Doi: 10.1007/s10151008-0409-7

29 Giordano P, Nastro P, Davies A, Gravante G. Prospective evaluation of stapled haemorrhoidopexy versus transanal haemorrhoidal dearterialisation for stage II and III haemorrhoids: three-year outcomes. Tech Coloproctol 2011;15(01):67-73. Doi: 10.1007/ s10151-010-0667-z

30 Rubbini M, Tartari V. Doppler-guided hemorrhoidal artery ligation with hemorrhoidopexy: source and prevention of postoperative pain. Int J Colorectal Dis 2015;30(05):625-630. Doi: 10.1007/s00384-015-2148-3

31 Ratto C, Parello A, Veronese E, et al. Doppler-guided transanal haemorrhoidal dearterialization for haemorrhoids: results from a multicentre trial. Colorectal Dis 2015;17(01):010-019. Doi: 10.1111/codi.12779

32 Elmér SE, Nygren JO, Lenander CE. A randomized trial of transanal hemorrhoidal dearterialization with anopexy compared with open hemorrhoidectomy in the treatment of hemorrhoids. Dis Colon Rectum 2013;56(04):484-490. Doi: 10.1097/DCR.0b013e $31827 a 8567$

33 Rørvik HD, Campos AH, Styr K, et al. Minimal Open Hemorrhoidectomy Versus Transanal Hemorrhoidal Dearterialization: The Effect on Symptoms: An Open-Label Randomized Controlled Trial. Dis Colon Rectum 2020;63(05):655-667. Doi: 10.1097/DCR.0000000000001588

34 De Nardi P, Capretti G, Corsaro A, Staudacher C. A prospective, randomized trial comparing the short- and long-term results of doppler-guided transanal hemorrhoid dearterialization with mucopexy versus excision hemorrhoidectomy for grade III hemorrhoids. Dis Colon Rectum 2014;57(03):348-353. Doi: 10.1097/ DCR.0000000000000085 